\title{
ESTAMPAS SOBRE JUAN DE ARGUIJO Y SUS CONTEMPORÁNEOS
}

\author{
GASPAR GARROTE BERNAL \\ Universidad de Málaga
}

\begin{abstract}
T a biografía que hoy manejamos de Juan de Arguijo es el resultado de un $\perp$ largo proceso que, iniciado apenas unos años después de la muerte del veinticuatro sevillano ${ }^{1}$, dio sus mejores frutos durante el siglo positivista, con los trabajos de Colón (1841)², Barrera (1864-1868)33, Castro (1866-1874)4, Asensio
\end{abstract}

\footnotetext{
${ }_{1}^{1}$ Rodrigo Caro, Varones insignes en letras naturales de la ilustrísima ciudad de Sevilla, ed. L. Gómez Canseco, Sevilla, Diputación, 1992, pp. 111-112.

2 Sonetos de D. Juan de Arguijo, Veinticuatro de Sevilla, ed. J. Colón y Colón, Sevilla, Francisco Álvarez y Compañía, 1841, pp. 8-12.

3 Cayetano Alberto de la Barrera, «Apéndice primero. Notas biográficas acerca de los poetas elogiados por Cervantes en el Viaje del Parnaso, recogidas por Don Cayetano A. de la Barrera», en Obras completas de Cervantes [...]. Tomo XII. Obras dramáticas [...], ed. C. Rosell, Madrid, Imprenta de Don Manuel Rivadeneyra, 1864, pp. 324-327; «Noticias biográficas del insigne poeta sevillano D. Juan de Arguijo», Revista de España, III (1868), pp. 79-89, y "Nuevas noticias biográficas del insigne poeta sevillano D. Juan de Arguijo», Revista de España, IV (1868), pp. 265-274, este último trabajo en realidad transcripción de la carta (Sevilla, 21-VIII-1868) que Juan José Bueno y Antonio Gómez Aceves enviaron a Barrera.

4 Adolfo de Castro, "XIV. Fundacion del Colegio de la Compañia de Jesus por Don Juan de Arguijo», en Historia del saqueo de Cádiz por los ingleses en 1596, escrita por Fr. Pedro de Abreu, religioso del órden de S. Francisco. Publícase con otras relaciones contemporáneas y documentos ilustratorios. Por acuerdo del Excmo. Ayuntamiento, Cádiz, Revista Médica, 1866, pp. 63-65, y ed., Varias obras inéditas de Cervantes, sacadas de códices de la Biblioteca Colombina, con nuevas ilustraciones sobre la vida del autor y el Quijote, por el Excmo. é Ilmo. señor Don Adolfo de Castro..., Madrid, A. de Carlos é Hijo, 1874, pp. 81-88.
} 
(1882-1883)5, Pérez Pastor (1907)6 y Rodríguez Marín (1907-1923)7. Las líneas maestras trazadas por estos autores fueron completadas con las aportaciones de Vranich (1972-1985) ${ }^{8}$ y otros críticos que mencionaré. A lo ya conocido quisiera ahora sumar algunos apuntes o estampas - en el sentido mironiano del término, razón por la cual me acogeré en adelante al flash back (¿o in medias res?) - sobre la relación de Arguijo, durante su sedentaria vida hispalense, con otros autores coetáneos.

\section{Un "exemplum" de Suárez de Figueroa (1617)}

Juan de Arguijo era prisionero de la imagen social que se había labrado desde la muerte de su padre en 1594, año en que inició su acelerada carrera por la pendiente dispendiosa que fue signo de la enriquecida burguesía sevillana del XVI, cuyos componentes concibieron el lujo y la ostentación como instrumentos que, con evidente dimensión política, emplearon frente a los rancios caballeros 9 . El 12 de octubre de 1599, Arguijo dilapidó una enorme suma para recibir a la marquesa de Denia en su finca de Tablantes - cercana a Sevilla-, donde había «casas principales», «molinos y almacén de aceite y olivares, viñas y cortijos de pan sembrar» ${ }^{10}$. Hacia 1590, el cortijo había sido comprado en subasta por el padre del poeta, cuando Gaspar de Arguijo se había transformado en un «auténtico terrateniente andaluz»11. La leyenda sobre Juan

5 José María Asensio, «Don Juan de Arguijo. Estudio biográfico», La Ilustración Católica, época $3^{a}$, año VI [pero VII], tomo VI, no 16 (5-XII-1882), pp. 185c-186c y 188a-189a («Parte primera. 15601599»); época $3^{\mathrm{a}}$, año VIII, tomo VI, no 19 (5-I-1883), pp. 225a-226c («Parte segunda. 1600-1623»); época $3^{\mathrm{a}}$, año VIII, tomo VI, n 22 (5-II-1883), pp. 255b-257a («Parte segunda. 1600-1623 [Continuación]»), y época 3 $3^{\text {a }}$, año VIII, tomo VI, nº 23 (15-II-1883), pp. 267c-269a («Parte segunda. 1600-1623 [Conclusión]»).

${ }^{6}$ Cristóbal Pérez Pastor, Bibliografía madrileña ó Descripción de las obras impresas en Madrid [...]. Parte tercera, Madrid, Tipografía de la Revista de Archivos, Bibliotecas y Museos, 1907, p. 330.

7 Francisco Rodríguez Marín, Pedro Espinosa. Estudio biográfico, bibliográfico y crítico [1907], ed. facs., pról. B. Molina Huete, Málaga, Universidad, 2004, pp. 50-51, 106-109, 122-132 y 139-140 y «Don Juan de Arguijo», en Nuevos datos para las biografías de cien escritores de los siglos XVI y XVII, Madrid, Tip. de la «Revista de Archivos, Bibliotecas y Museos», 1923, pp. 349-360.

8 Stanko B. Vranich, «Introducción biográfica y crítica» a Juan de Arguijo, Obra poética, Madrid, Castalia, 1971, pp. 7-23; «Lujo y ostentación de la clase media en Sevilla (siglo XVI)» [1976] y «Don Juan de Espinosa: poeta sevillano del siglo XVII» [1976], Ensayos sevillanos del Siglo de Oro, Valencia, Albatros Hispanófila, 1981, pp. 55-63 y 73-82; «Introducción biográfica» a Obra completa de Don Juan de Arguijo (1567-1622), Valencia, Albatros Hispanófila, 1985, pp. 13-28, y «El negociante tinerfeño Gaspar de Arguijo (1532-1594). Historia de un éxito», Anuario de Estudios Atlánticos, 26 (1980), pp. 561-612.

9 Vicente Lleó Cañal, Nueva Roma: mitología y humanismo en el Renacimiento sevillano, Sevilla, Diputación, 1979, pp. 16 y 27-31.

10 Francisco Rodríguez Marín, Nuevos datos..., op. cit., p. 353.

11 Stanko B. Vranich, «El negociante tinerfeño...», art. cit., p. 604. 
Estampas sobre Juan de Arguijo y sus contemporáneos

de Arguijo asentó que en el agasajo de 1599, «y en otras ostentaciones, gastó 20.000 ducados que tenía de renta y quedó pobre, retraído toda su vida»12. Más apegada a la realidad, una crónica, probablemente escrita por quien formó en la comitiva de la alta dama, Juan de Henestrosa, aseveraba que

vinieron a comer a Tablantes, casa de campo de don Juan de Arguijo, la mejor del Andalucía, y más bien aderezada de riqueza y vistosidad. Salieron a recibilla el dicho don Juan, que hizo la costa: comida la más espléndida que su Señoría hubo. Con él vino el marqués de Santa Cruz, don Martín Portocarrero, hermano del marqués de Villanueva, y don Fernando de Guzmán, Luis del Alcázar, don Pedro de Sandoval y otros caballeros. Y estos y los que venían comieron - el conde y mi señora la marquesa, aparte $-[\ldots] .^{13}$

La marquesa, esposa del duque de Lerma, «que ya en todo corría como primer ministro» de Felipe III, entró al día siguiente en la ciudad, procedente de Sanlúcar, donde había asistido al parto de su hija: «Correspondió bien Sevilla [...] con fiestas y demostraciones grandes» ${ }^{14}$. Lo curioso del caso es que el Arguijo que en sus sonetos había empleado la historia y la mitología clásicas como almacén de exempla para una doctrina moral, fue a su vez transformado en ejemplo - y la palabra solicita una y otra vez los poemas del veinticuatro - por Suárez de Figueroa en 1617, a cuento precisamente de su dispendioso recibimiento:

Lo que me suele provocar a más risa que lástima es el exceso con que algunos presentan, sin poner los ojos en la futura calamidad derivada de su desorden. En una ocasión de agasajo (sin tocarle) sé yo quién consumió dieciocho mil ducados de renta, en virtud de quien [sic] quedó pobre y retirado, sin que de la persona que pretendió obligar le viniese género de remuneración. ${ }^{15}$

En la leyenda que achacó la ruina de Arguijo exclusivamente a su generosidad para con poetas, artistas, jesuitas y demás, sin tener en cuenta la crisis comercial, demográfica y social sevillana de finales del XVI, este texto del Alivio $X$ de El pasajero tuvo que cumplir una muy temprana función

12 Efemérides del maestro Sebastián de Villegas, manuscrito de la Biblioteca Colombina citado por Francisco Rodríguez Marín, Pedro Espinosa..., op. cit., p. 126, n. 2; cfr. también Adolfo de Castro, Varias obras inéditas..., op. cit., p. 81, n. 2.

${ }^{13}$ Edito el texto transcrito paleográficamente por José Martínez Jiménez, «Visita de la marquesa de Denia a Sevilla», Archivo Hispalense, 2a época, V, 12-14 (1945), pp. 373-377 (la cita, en p. 374).

14 Diego Ortiz de Zúñiga, Anales eclesiásticos y seculares de la muy noble y muy leal ciudad de Sevilla, metrópoli de la Andalucía [1667], ed. facs. J. Sánchez Dubé, Sevilla, Guadalquivir, 1988, IV, p. 194.

15 Cristóbal Suárez de Figueroa, El pasagero. Advertencias utilísimas a la vida humana..., ed. F. Rodríguez Marín, s. 1., Renacimiento, 1913, p. 333 (en pp. viii-ix, este editor identificó como Arguijo al personaje aludido). 
ahistorizadora, y no sólo por el velo que encubre y veda el nombre de su protagonista.

\section{Juan de la Cueva se desdice a tiempo (1599-1605)}

Frente al integrado Juan de Arguijo, veinticuatro del Cabildo secular, el discurso de la marginalidad hispalense se burló, en diez sonetos, de la fastuosa llegada de la marquesa de Denia («el martes en la tarde pare el monte») y de un poder militar reducido a meros alardes y naumaquias: «salen diez mil soldados a campaña / y llegan las galeras a la puente» ${ }^{16}$. Uno de estos poemas, «He aquí que en refrescar los caminantes / el señor Veinticuatro se ha extremado...», fue glosado al margen izquierdo de este verso 2: «Do[n] Ju[an] de Arguijo»17. La apostilla sólo aclara la referencia de dicho endecasílabo, y es así concisa señal de crónica burlesca sobre la fortuna empleada por nuestro poeta aquella tarde de campo. En los pasos de Benítez Claros - que, a buen seguro, por seguir la inconsistente intuición de Benito Ruano, no se atrevió a descartar la autoría arguijiana para este soneto-, Simón Díaz lo atribuyó erróneamente al veinticuatro ${ }^{18}$.

Al recibimiento que Arguijo dispensó a la marquesa aludiría asimismo el verso 3, «hospeda, cuando venga, a un semideo», de un undécimo soneto, debido a Juan de la Cueva, y que supongo escrito, como los otros diez, antes de que el 6 de noviembre de 1599 terminaran los festejos:

\footnotetext{
«Si quieres por un Píndaro venderte y que te llamen el segundo Orfeo, hospeda, cuando venga, a un semideo y sácale a orear, que puedan verte.

"Saca de cuando en cuando, como suerte, un soneto a Aquiles o Teseo
}

${ }^{16}$ Cfr. Eloy Benito Ruano, «Jornada y sátira sevillanas de la Marquesa de Denia (1599)», Archivum, XV (1965), pp. 142-156, quien publicó los diez sonetos que he mencionado (conservados en la Biblioteca de la Universidad de Oviedo, Mss. 63 y 64, y en BNM Mss. 861 y 19387), propuso como posible la autoría de Juan de la Cueva para «He aquí que en refrescar los caminantes...» y dio en «intuir la paternidad» de Arguijo para «Poetas en nombre sólo...», contraataque en quintillas ante el discurso «de disconformidad» por los derroches del Concejo durante aquellas fiestas. A la bibliografía de Benito Ruano sobre el asunto deben añadirse los trabajos de Asensio y Martínez Jiménez citados supra.

17 Canciones místicas (tejuelo), BNM Ms. 861, p. 621. Este manuscrito colecciona (pp. 620-624) cinco de los diez sonetos mencionados.

18 Rafael Benítez Claros, ed. Juan de Arguijo, Obras completas, Santa Cruz de Tenerife, Romerman, 1968, p. 277; José Simón Díaz, Bibliografía de la literatura hispánica, V, Madrid, CSIC, 19732, p. 625 ( $\mathrm{n}^{\mathrm{o}}$ 4325). Francisco Rodríguez Marín ni se planteó esa supuesta paternidad arguijiana (Pedro Espinosa..., op. cit., p. 126, n. 2). 


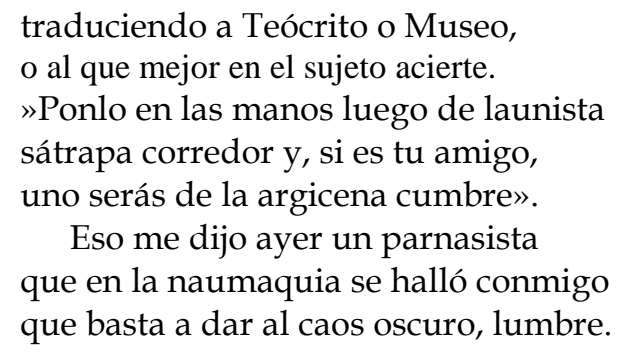

Ese launista, que en el soneto actúa como correveidile (corredor) y dictador (sátrapa) del gusto poético, podría ser error - del manuscrito o de la transcripción de Rodríguez Marín- por laurista, derivado bien de Laura, nombre que indefectiblemente remite al petrarquismo y a sus practicantes; bien de laura, «especie de lugar o villa en que vivían antiguamente los monjes en una especie de casitas acomodándose uno o dos en cada una. Los monasterios de cartujos representan de algún modo estas lauras» ${ }^{19}$; bien de laurel, planta que, en su relación con Apolo, dios de la poesía, ciñe «las sienes de los poetas» ${ }^{20}$. Las tres posibilidades parecen apuntar a Herrera, central en el petrarquismo sevillano del momento, clérigo y considerado el Divino por sus contemporáneos. Como veremos enseguida, la indirecta sobre Herrera tendría aquí su razón de ser. No hay que perder de vista, con todo, que launa es «lámina o plancha de metal. Es contracción de la voz lámina ${ }^{21}$ », aunque no se ve bien qué función representaría en este contexto tal referencia. Por último, el error podría haber afectado a de launista, en cuyo caso habría que leer del aunista, derivado burlesco - que además aseguraría la rima - de auna, «a un mismo tiempo y sazón» ${ }^{22}$, por lo que el contexto tendría entonces este sentido: 'del a un mismo tiempo sátrapa y corredor'. Por su parte, la naumaquia del soneto alude «al simulacro de combate naval en el Guadalquivir» celebrado en honor de la marquesa ${ }^{23}$.

En el maledicente poema, Cueva, que había vuelto a su Sevilla natal antes de 1595 y allí permaneció hasta 160624, criticaba entre otras cosas los sonetos

\footnotetext{
19 Esteban de Terreros y Pando, Diccionario castellano con las voces de ciencias y artes, ed. facs., Madrid, Arco Libros, 1987, II, p. 427.

20 Sebastián de Covarrubias, Tesoro de la lengua castellana o española, ed. M. de Riquer, Madrid, Altafulla, 1987, p. 754.

${ }^{21}$ Academia Española, Diccionario de la lengua castellana... [1732], III, ed. Facs., Madrid, Gredos, 1976, p. 369b.

22 Tesoro de la lengua castellana., p. 170.

${ }^{23}$ Francisco Rodríguez Marín, Pedro Espinosa..., op. cit., pp. 129-130, que dio a conocer el soneto y lo anotó, incluyendo el sentido de argicena, pero sin comentar el extraño launista.

24 José Cebrián, Estudios sobre Juan de la Cueva. "No tengo duda qu'estrañéis mi nombre», Sevilla, Universidad, 1991, pp. 15-35. Cfr. asimismo Francisco Rodríguez Marín, Pedro Espinosa..., op. cit., p. 106, n. 4, que publica también un «enrevesado soneto» inédito, «Joviano, otro Mecenas
} 
XXVII (sobre Aquiles) y XXXIX (sobre Teseo) del veinticuatro 25 , a quien censuró como autor nada original por traducir «a Teócrito o Museo». Tal ausencia de novedad aseguraba, según el satírico, formar parte de «la argicena cumbre», alusión al sobrenombre poético de Arguijo (Argío, como lo llamó Medrano ${ }^{26}$ ) y a su academia, donde el mecenas-poeta ofrecería sus sonetos a la recepción de unos amigos que los copiarían y extenderían por Sevilla. Esta última suposición es de Rodríguez Marín²7, que presentó a Caro, Jáuregui, Jiménez de Enciso, Rioja, el tercer duque de Alcalá, Fonseca, Medrano, Fernández de Andrada, Calatayud, Robles, Porras de la Cámara, Colindres y Serna frecuentando, todos o muchos de ellos, «la opulenta casa del veinticuatro», donde - si no en la otra famosa tertulia, la del pintor Pacheco - los conocería Espinosa durante su estancia en Sevilla ${ }^{28}$. Pero esa lista no es sino conjetura pancrónica para el período aproximado de 1596 a 1605 (por ejemplo, Medrano volvió a Sevilla en 1602 $)^{29}$.

Pero volvamos a las críticas contra Arguijo. Ya se sabe cómo se las gastaba Juan de la Cueva - «digo lo que quiero»- con muchos de los que despectivamente llamó filopoetas y entendió movidos por el «odio y rencor» ${ }^{30}$ : en su «Epístola a don Juan de Arguijo», casi contó lo que pasó con su poema «A Casio»:

Porque le hice a Casio un mal soneto (no digo bien, porque es mejor que bueno), se rebeló el amigo más perfeto.

En ese amigo hay una alusión a «¿Herrera?», según la más que plausible hipótesis de Gallardo, quien se basó para formularla en unas pistas que en la

excelente...» (pp. 107-108, n. 2) dedicado, según él, a Arguijo por un tal Pamones, contrario a Cueva.

${ }^{25}$ Ya advirtió Francisco Rodríguez Marín, Pedro Espinosa..., op. cit., p. 129, n. 5, que sobre Aquiles y Teseo había tratado Arguijo en esos dos sonetos, lo que de paso sirve para obtener el término ante quem de ambos poemas. Cito por la numeración de Versos de don Juan de Arguijo. Año de mil seiscientos y doce, en Cisnes del Betis (tejuelo), BNM Ms. 10159.

${ }^{26}$ Dámaso Alonso y Stephen Reckert, Vida y obra de Medrano II. Edición crítica de sus obras, Madrid, CSIC, 1958, pp. 163, 171 y 222.

27 Pedro Espinosa..., op. cit., pp. 127-128.

28 Pedro Espinosa..., op. cit., pp. 108-109 y 122.

29 Sobre el precario conocimiento de la academia de Arguijo, cfr. José Sánchez, Academias literarias del Siglo de Oro español, Madrid, Gredos, 1961, pp. 203-207 y Willard F. King, Prosa novelística y academias literarias en el siglo XVII, Madrid, RAE, 1963, p. 27.

30 Cito de la «Epístola a D. Juan de Arguijo» publicada en Bartolomé José Gallardo, Ensayo de una biblioteca española de libros raros y curiosos... [1863-1889], ed. facs., Madrid, Gredos, 1968, III, cols. 692-696. Gallardo anotó que en el manuscrito que la conserva está «tachado el nombre de D. Juan de Arguijo». 
epístola serían explícitas para Arguijo: el «amigo» no debería ser considerado un «Homero» por hacer «centones de los versos / ajenos, cual el otro cocinero» (entiendo que las Anotaciones a Garcilaso), ya que, además de «ser medidos y ser tersos», de los «puntos de ortografía nueva» (una obsesión herreriana) y del «ir caldeados de diversos», hay más cosas que «el sabio aprueba» en los metros: así, «la invención» 31 . Esto último concuerda con el reproche contra el veinticuatro que figuraba en el soneto de 1599. La ira de Herrera estimularía a Cueva, quien en su epístola aseguró a Arguijo que multiplicaría por doscientos una materia, la del poema a Casio, que tanto había transitado el veinticuatro: «Os prometo, don Juan, hacer docientos / de fábula y de historia deste modo» 32 .

Juan de la Cueva - lo hemos visto - conocía algunos sonetos de Arguijo, aunque no por asistir a su academia, inasistencia que fue una suposición de Rodríguez Marín apoyada en la epístola mencionada ${ }^{33}$, y que ahora voy a confirmar precisamente por leerla de forma diferente a la suya. El polémico poeta nos legó en ella un valioso instrumento para datar unas reuniones en que había participado, puesto ya el pie en el estribo, Fernando de Herrera ${ }^{34}$. Lo que de esos versos se desprende es que Cueva sondeó, sin éxito, la posibilidad de tener asiento en aquella tertulia: dada la autoridad que Herrera ejercía sobre los cisnes del Betis, el soneto «A Casio», rechazado por el Divino, le habría supuesto a su autor, entre su regreso a Sevilla (antes de 1595) y la muerte del comentarista de Garcilaso (1597), no sólo el odio de Herrera, sino también el desprecio de alguno de los academicistas de Arguijo. Esto provocó entonces una airada contestación de Cueva que, extensiva a todos ellos, habría llegado a oídos del veinticuatro. Lo demás - el soneto «Si quieres por un Píndaro venderte...», de finales de 1599, y algún otro texto ${ }^{35}$ - vino rodado.

31 Cfr. Bartolomé José Gallardo, op. cit., III, cols. 677-678, que publica el soneto de Cueva a Casio y vuelve a indicar que la epístola mencionada está dedicada «á D. Juan de Arguijo (si es que no leo mal el nombre borrado)». Pero Francisco Rodríguez Marín dio por hecho que «A Casio» pretendía «eclipsar las glorias» de Arguijo, con lo que interpretó mal la epístola (Pedro Espinosa..., op. cit., p. 128 y n. 2).

32 Apud Bartolomé José Gallardo, op. cit., III, col. 694. Los doscientos sonetos imaginados por Cueva son el doble de la centuria que se habría propuesto hacer Arguijo (cfr. infra).

33 Pedro Espinosa..., op. cit., p. 128.

34 El 26 de marzo de 1597, en una carta a Céspedes, Herrera no desmentía que estuviera alojado en casa de Arguijo. La carta fue publicada por Jesús Rubio Lapaz, Pablo de Céspedes y su círculo. Humanismo y Contrarreforma en la cultura andaluza del Renacimiento al Barroco, Granada, Universidad, 1993, pp. 381-382 y 507 (facsímil 11: Archivo de la Catedral de Granada, libro 58, fol. 165r), quien comentó su literalidad (pp. 128, n. 70 y 155, n. 129).

35 Una elegía con ataques más o menos velados al veinticuatro y su academia; en cuanto al soneto de Cueva que aludiría al de Arguijo sobre Hércules (Pedro Espinosa..., op. cit., pp. 129-130), Francisco Rodríguez Marín advirtió más tarde su error interpretativo (ibid., pp. x-xi de las «Adiciones» de 1909, situadas como apéndice en la ed. facs. cit.). Por fin, el contenido de «Cinco eses ilustran la grandeza...», otro poema dedicado por Cueva al veinticuatro (Bartolomé José 
Pero adviértase que, en su epístola, Cueva se arrepiente de cierto suceso y pide disculpas a su receptor:

Sabéis, don Juan, que hice un desvarío, y entre algunos que he hecho de esta suerte, en aqueste salió de madre el río.

Por eso trata antes de «haceros manifiesta / mi voluntad ardiente y ofrecida / a la vuestra», y de justificar ese «desvarío», que causó «un dolor que me procura / acabar, y aun es justo que lo haga». El sufrimiento que iba a matarle había empezado con el «rencor» con que «se rebeló el amigo más perfeto» - quizá Herrera, como vimos - y con la discusión entre Cueva y alguien cercano a Arguijo:

\author{
Le pregunté qué título tenían \\ con vos mis versos, qué lugar o asiento \\ vuestros academicistas les darían. \\ Respondióme (bien fuera de mi intento, \\ y de lo que a mis números se debe \\ y de lo que de vos y dellos siento) \\ que, si del sacro coro de las Nueve \\ mi acetación hubiera de alcanzarse, \\ fuera más fácil impetrar un breve.
}

No era Juan de la Cueva hombre que aguantara estas cosas: «Cansóme» «y preguntéle con algún desgusto / si los lugares que ellos ocupaban / se los dio por herencia el sacro Augusto». De modo que, con su epístola al veinticuatro, Cueva trató de transmitir a «don Juan, honor del siglo y mi esperanza», el que su enemistad había sido provocada por aquellos dos de quienes silencia los nombres. ¿Qué razón había para tal cambio de actitud, acaecido en cuestión de meses?

Pues que, en efecto, Arguijo tenía en sus manos, desde el 15 de noviembre de 1600, la esperanza de Cueva. Tras lograr ese año la aprobación y el privilegio de impresión para la Conquista de la Bética, poema épico en veinticuatro cantos sobre «la restauración y libertad de Sevilla por el Santo Rey Don Fernando», Juan de la Cueva solicitó al Cabildo secular sevillano, en la fecha mencionada, que costeara la publicación de la obra; la petición fue concedida en la sesión capitular del 9 de marzo de 1601 - «haciendo a su autor, en premio de su

Gallardo, op. cit., III, col. 660; Francisco Rodríguez Marín, Pedro Espinosa..., op. cit., p. 127, n. 1), muestra que tuvo que ser posterior al enfrentamiento de Cueva con Arguijo. 
trabajo, la merced que pide»-, tras el informe favorable del jurado Cristóbal Xuárez... y de Juan de Arguijo ${ }^{36}$.

Éste, por tanto, empezó sufriendo los ataques de Juan de la Cueva, al menos desde finales de 1599. Como ya podemos fechar la «Epístola a don Juan de Arguijo» entre el 15 de noviembre de 1600 y el 9 de marzo de 1601, hemos de concluir que apenas un año después de 1599 Cueva pidió perdón al veinticuatro, quien se lo concedió y terminó aprobando la Conquista. Rodríguez Marín había fundamentado sus hipótesis sobre las relaciones entre ambos poetas, en la datación de 1585 para todo el Viaje de Sannio ${ }^{37}$, pero ahora sabemos que esa fecha cubre sólo sus cantos I-IV, pues el V, cuya estrofa 71 es un elogio de Arguijo, fue compuesto mucho después, hacia 1604-160538. Con tal octava pagaba Cueva la intercesión de su antiguo satirizado para que el Cabildo abonara la publicación de la Conquista en 1603. Y aún se sigue sosteniendo que la comercialización de la literatura es fenómeno bien reciente...

Todo había sido, por tanto, al revés de como lo pintó Rodríguez Marín, que cuando señaló que, al aprobar la Conquista, Arguijo estaba «devolviendo bien por mal» ${ }^{39}$, al menos pretendía dibujar un zig-zag de odio y amor entre ambos, que tampoco se dio. Sin embargo, en el Sannio quedó un nexo que conectaba su estrofa V, 71 con el soneto satírico de 1599: Juan de la Cueva empleaba de nuevo la voz Píndaro para llamar gravemente - ya no para aludir burlescamente - a Arguijo. El elogio de éste se presenta como un vaticinium ex eventu en boca de la Virtud, y de ahí el tiempo futuro empleado:

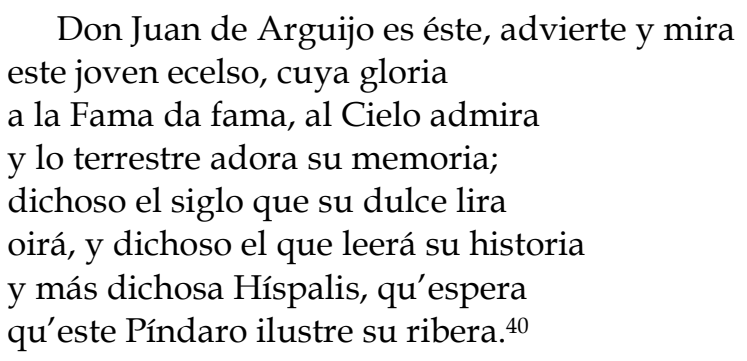

Presentar como joven a un Arguijo que en 1604 tenía 37 años cuadra sólo con la cronología interna y ficticia del vaticinio, pero también podría interpretarse que Cueva habría querido mostrar - para hacerse perdonar sus

\footnotetext{
36 José Cebrián, op. cit., p. 34; sobre el poema, cfr. el capítulo del mismo libro «En torno a la Conquista de la Bética», pp. 115-124.

37 Pedro Espinosa..., op. cit., p. 126.

38 Cfr. la separata de José Cebrián, «El Viaje de Sannio de Juan de la Cueva», pp. xxv-xxvii, en Juan de la Cueva, Viaje de Sannio, ed. J. Cebrián, Madrid, Miraguano, 1990.

39 Pedro Espinosa..., op. cit., p. 130, n. 2.

40 Juan de la Cueva, Viaje de Sannio, ed. cit., p. 139.
} 
anteriores ataques contra el veinticuatro - , que el elogio lo tenía escrito mucho tiempo antes. En cualquier caso, esta alabanza responde al automatismo del subgénero del que forma parte ${ }^{41}$; sin embargo, escapa a esa esclerosis la concreta referencia a eso que se interpretará del veinticuatro, es decir, y fuera del vaticinium ex eventu, que se ha interpretado: «dichoso el que leerá su historia».

Esa historia podría ser la vida de Arguijo cuando fuere escrita, una obra historiográfica de su autoría o un conjunto ficticio que relatase procesos. Estas tres hipótesis se fundan en las recurrencias de la voz historia en el Sannio, donde vale por la propia vida de éste («mi llorosa historia»)42. Pero también por «historia verdadera»43, que por tanto está sujeta a labor historiográfica (history) como hecho sucedido de verdad y que se opone a la fábula y al juego ( $i$ 'teatro', joc, play?) ${ }^{44}$; no en vano, la historiografía es tarea de autores -Mexía, Fuentes, Fernández de Córdoba - de verdaderas historias de reyes ${ }^{45}$, aunque puede ser falsa, en cuyo caso quien la inventa merece el olvido ${ }^{46}$. Por último, historia es también un relato mitológico que «leo» $\mathrm{o}$ «que hallo escrito» 47 , como las historias de Marte, Apolo, Neptuno y Hércules48; completa esta tercera acepción - 'ficción', store - el saber que la poesía elegíaca «es como historia o narración en verso»49 y que el poeta puede escribir de "gloriosas / hazañas que a la historia son debidas», aunque «no ha de ser tan puntual» como el cronista50: es la conocida distinción aristotélica, por la que se indica «que seré historiador y no poeta / en proceder, y en todo verdadero» ${ }^{51}$.

Este último es el sentido que con mayor probabilidad cuadra con la historia que figura en $\mathrm{V}, 71$ : unos poemas sobre fábula e historia -como el mismo Cueva había escrito hacia 1600-1601 en su epístola a Arguijo-, inéditos, que sólo unos pocos podían degustar. Dicho de otro modo: a la altura de 1604-1605, Arguijo disponía de una historia en sonetos, que por diversos cauces había sido comunicada a unos cuantos felices interlocutores, entre los que se hallaba Juan de la Cueva.

41 Gaspar Garrote Bernal, «La retórica de los poemas laudatorios de poetas en los siglos XVI y XVII», en J. A. Hernández Guerrero (ed.), Retórica y Poética, Cádiz, Seminario de Teoría de la Literatura, 1991, pp. 159-173.

42 Viaje de Sannio, IV, 32f , ed. cit., p. 103.

43 Ibid., IV, 67e, p. 112.

44 Ibid., II, 78bc, p. 53, aunque aquí esta acepción se la aplica Marte a sí mismo.

45 Ibid., V, 68f, 69a y 74f, pp. 138 y 140.

46 Ibid., V, 81d, p. 141.

47 Ibid., III, 47f y 49c, p. 67.

48 Ibid., III, 12e, 32b, 47g y 49f, y 122e, pp. 58, 63, 67 y 85 .

49 Ibid., IV, 61g, p. 110.

50 Ibid., IV, 66ef y 67a, p. 112.

${ }^{51}$ Ibid., III, 132cd, p. 88. 


\section{Mesa y el parnasianismo de Arguijo (1606)}

Hemos visto a Cueva emplear los términos academicistas (h. 1600-1601) y parnasista (1599), ante lo que cabe reflexionar sobre cómo el sufijo -ista deriva en los dos respectivos contextos un sentido satírico y despectivo. Pero más me interesa ahora explorar el que la unión de parnasista y Píndaro en el soneto que Cueva compuso en 1599 bien podría apuntar de nuevo a Herrera. Sospecho que el Viaje de Sannio trasluce un resquemor de Juan de la Cueva - pero esto será asunto de otras páginas - contra la élite mal-larista que, encabezada por el Divino, rigió los destinos de la intelectualidad sevillana durante décadas. A esa élite terminaría sumándose el Arguijo satirizado en 1599 mediante la unión de Píndaro y el Parnaso, unión que, asentada en las Anotaciones herrerianas (1580), pudiera haber reinterpretado con sorna Juan de la Cueva:

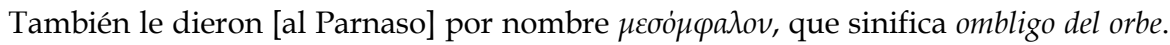
Porque dizen que (como trae esta fábula de Píndaro en el Libro 9) queriendo conocer Iúpiter el lugar que fuesse medio del mundo, envió dos águilas del Oriente i Occidente, que cansadas de volar pararon en la cima de Parnasso. ${ }^{52}$

Parnasista: quien se cree el ombligo del mundo, según autoriza Píndaro y cuenta Herrera. He aquí una posible paráfrasis del sentido satírico que la voz pudo tener en el soneto que el marginado Cueva dedicó al integradoArguijo, tan cobijador de academicistas. Sentido desde luego muy distinto al que la crítica de los siglos XIX y XX forjó como tópico sobre un Arguijo poeta parnasiano avant la lettre. Pero, ¿podría asentarse dicha inercia interpretativa sobre cierto soneto poco conocido que Cristóbal de Mesa dedicó «A don Ivan de Argviio [sic], Veintiquatro de Seuilla»?:

La flor del nombre de Aiax, y Iacinto,

Ya dulce en vna, y graue en otra parte,

Simbolo es de tu lira, y hilo el arte,

Con que sales de vario laberinto.

Subiendo del segundo al cielo quinto,

Donde Mercurio, Venus, Febo y Marte,

Facundia, amor, saber, poder reparte

Tu claro ingenio, y mas q[ue] humano instinto.

$\mathrm{Al}$ sumo hazedor del vniuerso

Imitas, grande artifice, en la traça

De tu noble argumento sin segundo.

No embidia bronze, o marmol tu alto verso,

52 Fernando de Herrera, Anotaciones a la poesía de Garcilaso, ed. I. Pepe y J. M. Reyes, Madrid, Cátedra, 2001, p. 436. 
Que qual al mundo menor todo lo abraça, Siendo inmortal mientras viuiere el mu[n]do. ${ }^{53}$

Creo que el noble argumento al que se refiere este soneto equivale a la historia de Cueva, y me parece significativo que Mesa comience, entre sus abundantes referencias mitológicas, con un Jacinto con el que coincide el nombre de otro personaje, el santo celebrado por Arguijo en 1595, en su canción «En la fiesta de la canonización de san Jacinto que hicieron en Sevilla», y que también transmite BNM Ms. 10159. Este poema promete al canonizado una gloria que dejará pequeña a la gozada por las pirámides de Egipto:

Pensó el egipcio, mas pensaba en vano, fijar su nombre en la sublime altura de soberbias pirámides: ¿qué gloria pudo permanecer de tal locura, si siendo al fin su pensamiento vano pequeño rastro deja su memoria? (vv. 14-19)

Ni que decir tiene que Arguijo en 1595 y Mesa en 1606 («no envidia bronce o mármol tu alto verso») pensaban en el Horacio que seguro se sentía de que la eternidad quedaba reservada, más que para el bronce y las pirámides, para su arte: Exegi monumentum aere perennius / regalique situ pyramidum altius (Carm. III $30,1-2)$. El propio veinticuatro lo había hecho también, pero en referencia al Mausoleo, en su soneto XXXV:

Labra Artemisia el grande Mausoleo, que los altos pirámides afrenta del egipcio soberbio $y$, no contenta, busca a su ilustre fe mayor trofeo. (vv. 1-4)

Por lo demás, el verso 12 de Mesa pudiera espejear no sólo los de Horacio, sino también el 13 de este soneto de Arguijo, que trata de un tema -amor más allá de la muerte - que sería del gusto de Quevedo:

que de su injuria puede defenderte mi pecho más que el bronce y mármol firme y eternizar mi amor y tu memoria. (vv. 12-14)

53 Valle de lagrimas y diuersas Rimas de Christoual de Messa [...], Madrid, Juan de la Cuesta, 1607 (pero el colofón es de 1606), fols. 119v-120r. Manejo el ejemplar BNM R-7831. 
Tildar de parnasiana la poesía del veinticuatro no deja de ser un recurso tan imaginístico como simplificador, cuando no sólo flagrante anacronismo ${ }^{54}$; la etiqueta también hubiera servido, por cierto, para algunos sonetos de Cristóbal de Mesa, a quien Clarín podría haber adjuntado a la nómina que dispuso cuando, comparando a poetas como Arguijo, los Argensola, Jáuregui y Góngora con los parnasianistas del XIX, estableció en cierto artículo del Palique (1894) que $\mathrm{su}$ «frialdad», «muchas veces semejante a la del mármol de la estatua», es la de unos «enamorados de la forma» que fueron «hábiles para dejar en el estrecho marco bien cincelado de un soneto de bronce o de oro un cuadro histórico, un momento de la naturaleza, un estado del alma»55. El tópico ha calado en el caso de Arguijo, pero el bronce y el mármol son más bien, en la poesía del XVII, asunto de Horacio y no de Heredia, por mucho vaticinium ex eventu que la crítica pretenda interponer.

\section{Lope y unos amigos (1602)}

La amistad entre Arguijo y Lope de Vega duró casi un cuarto de siglo, desde que el veinticuatro corrió con los gastos de publicación de La hermosura de Angélica con otras diversas rimas. Esa generosidad volvió a tener, como en el caso de Cueva, recompensa gráfica: en la edición de 1602, tanto la portada del libro como la portadilla que abre la «Segvnda parte de las Rimas de Lope de Vega Carpio. A don Iuan de Arguijo. Veintiquatro de Seuilla», incluyen el escudo de don Juan, flanqueado, a la derecha, por el lema Virtud y nobleza, y a la izquierda por el de Arte y naturaleza ${ }^{56}$.

Lope congregó, en los preliminares de esta obra, a tres amigos que cantaran las excelencias no del autor, sino del mecenas ${ }^{57}$. $Y$ en eso consiste este pórtico: en una alabanza de la amistad mutua entre el poeta que componía y el poeta que lo sustentaba. El sentimiento y «de la amistad la fuerza no vencida» ya habían sido ensalzados por el mismo Arguijo en su soneto XVII. Ahora, las

54 Contra el «repetido tópico» del parnasianismo arguijiano reaccionó, en solitario, José Lara Garrido, «"Gravedad del concepto": clasicismo y moral contrastiva en Juan de Arguijo», Del Siglo de Oro (métodos y relecciones), Madrid, Universidad Europea-CEES, 1997, pp. 148-150.

55 Leopoldo Alas Clarín, «XI. Los trofeos, por José María de Heredia» [12-VII-1893], Obras completas IV Crítica (Segunda parte), ed. L. Bonet et al., Oviedo, Nobel, 2003, pp. 1819-1828 (la cita, en p. 1822). 56 La hermosvra de Angelica, Con otras diuersas Rimas. De Lope de Vega Carpio. A don Iuan de Arguijo, Veintiquatro de Seuilla, Madrid, Pedro Madrigal, 1602. Describo portada y portadilla (fol. 242r) del ejemplar BNM R-5135. A lo indicado por Felipe B. Pedraza (en su ed. de Lope de Vega, Rimas I [Doscientos sonetos], Madrid, Universidad de Castilla-La Mancha, 1993, p. 124, n. 5-6), sobre la «viñeta» de la portada de 1602, añádase que se trata del escudo de Arguijo - como ya señaló Rafael Benítez Claros, ed. cit., p. 26-, fotografiado por José Gestoso y Pérez, «La casa de D. Juan de Arguijo», Bética. Revista Ilustrada [Sevilla], II, 16 [20-IX-1914], 7 pp. sin numeración.

${ }^{57}$ La hermosvra..., ed. cit., fol. I 3rv. 
amistades de Lope hacen lo que pueden: el deslavazado soneto «A don Juan de Arguijo, don Luis de Alvarado» llama al protector «clarísimo Mecenas, honra y gloria / de todo lo mejor que el Betis cría»; Arguijo, al componer también poesía, supera a Cornelio Galo, lo que además realza a un Lope trasunto de Virgilio: «pintar para el que pinta es rico empleo, / que sólo estima el don el que le entiende». «Don Baltasar de Luzón y Bobadilla, a D. Juan de Arguijo» alude a la tópica promesa, adjudicada aquí a Lope, de componer en su honor: «que me ha dicho que querría / retratar de vos un día / un perfecto cortesano», sintagma este último con que La Dragontea (1598) ya había denominado al veinticuatro: «[...] aquel don Juan de Arguijo sevillano, / en quien se vee, por gracia y gallardía, / la imagen de un perfeto cortesano»58. Por fin, «A don Juan de Arguijo, don Francisco Niño del Carpio», apela al sentimiento religioso del mecenas, si no es que juega con una hipérbole sacro-profana:

\author{
Siendo Dios sumo tesoro \\ y tan enseñado a dar, \\ le ofrecemos en su altar \\ tal vez la plata y el oro. \\ Si a Lope podéis dar vos \\ los versos que os da, mirad \\ que llevan la voluntad \\ para que imitéis a Dios.
}

¿«Para que imitéis a Dios»? Las palabras de Mesa en 1606 cobran ahora nuevo sentido: «Al Sumo Hacedor del universo / imitas, grande artífice». Mucho debían de esperar todos de tan alto mecenas (quiero decir, poeta).

\title{
5. Lope (u Octavio) desconcertarán a unos críticos futuros (1613)
}

Incluso durante los anni horribiles del sevillano, retraído en la casa profesa de los jesuitas hispalenses para ponerse a salvo de sus muchos acreedores (16091616), es muy probable que Lope y Arguijo mantuvieran un contacto epistolar. De ello es indicio la literaturización que en los versos 2113-2134 de La dama boba (1613) presenta a Octavio recordando el escrutinio que, en la biblioteca de su hija, hizo con una intención no distinta - «se los quise quemar»- de la que animó a los allegados de don Quijote:

Historia de dos amantes, sacada de lengua griega;

58 Obras completas de Lope de Vega, I. Obras no dramáticas. I, ed. J. de Entrambasaguas, Madrid, CSIC, 1965, p. 242. 


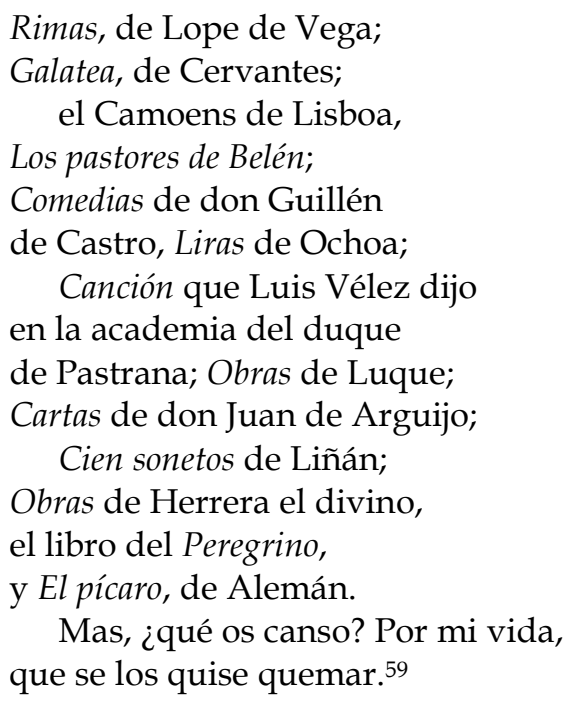

Como en botica, aquí hay de todo. Octavio se refiere no sólo a los «librillos» de Nise (la traducción de la Historia de dos amantes; La Galatea de Cervantes; la poesía de Camoens; las Comedias de Guillén de Castro; Algunas obras de Herrera, y el Guzmán de Alfarache de Alemán), sino también a sus «papeles y escritos varios», entre los que figurarían la canción de Vélez de Guevara leída en su correspondiente academia, las liras de Ochoa, las obras de Luque y cien sonetos de Liñán, amén de las tan traídas y llevadas «Cartas de don Juan de Arguijo».

La mención de esta supuesta obra ha desconcertado a toda la crítica: «¿Son, quizá, los cuentos, agudezas y chistes que coleccionó el poeta?»60; «Lope cita» "como un libro conocido en la época, Cartas de don Juan de Arguijo, de las que no existen otras referencias» ${ }^{61}$; la «enigmática alusión a la producción epistolar» de Arguijo apuntaría a «un cuerpo de cartas» «de valor literario tal como para merecer su inclusión entre las más célebres obras de su época», «sin embargo, nada de esto ha llegado a nosotros»62; Lope da «noticia» «sobre la supuesta producción epistolar de temática literaria desarrollada por Arguijo» ${ }^{63}$. Pero probemos a leer cartas como si el Fénix no hubiera sido filólogo, que es lo que, a tenor de esos comentarios, parece que fue: es decir, leamos la palabra en

\footnotetext{
59 Lope de Vega, La dama boba, ed. D. Marín, Madrid, Cátedra, 198710, pp. 146-147 (la data del autógrafo de esta comedia [Madrid, 28-IV-1613], en p. 53).

60 Santiago Mototo, Lope de Vega y Don Juan de Arguijo, Sevilla, Imprenta del Arenal, 1935, p. 29.

${ }^{61}$ Rafael Benítez Claros, ed. cit., p. 256, n. 57.

62 Stanko B. Vranich, Obra completa..., ed. cit., p. 418.

63 Mercedes Cobos, «Carta inédita "De don Juan de Espinosa cerca de la poesía oscura a don Juan de Arguijo"», Con Dados de Niebla [Huelva], 4 (octubre 1986), p. 47, n. 2.
} 
minúscula y sin cursiva. De hecho, el latín charta significa 'papelote, folio suelto', y una carta no tenía por qué transmitir necesariamente una epístola: varias podían formar un cartapacio, por ejemplo de poemas autógrafos. Creo que estamos realmente ante la típica fusión barroca entre vida y literatura: cuando Lope incluyó en la ficción dramática al autor de esas cartas, estaba indirectamente haciendo lo mismo con quien las había recibido. Dicho de otra forma: Octavio había revisado la biblioteca de Lope de Vega - de quien este otro escrutinio menciona tres obras (Rimas, Pastores de Belén y El peregrino) - , y hallado las colecciones de poemas escritos por Arguijo que poseería su viejo amigo.

\section{Para la invención de un marbete: Ibarra y la " escuela poética sevillana" (1623)}

Con la aprobación firmada por Lope de Vega en Madrid, a 15 de agosto de 1623, se publicaba el Encomio de los ingenios sevillanos, libro que recibió el privilegio el 30 de agosto de ese mismo año64. Su autor, Juan Antonio de Ibarra, aprovecha la ocasión de unos festejos religiosos para esbozar la historia de la que mucho tiempo después sería llamada escuela poética sevillana, con ensayo inicial de la compartida magnificencia de la ciudad y sus vates: «No es la menor alabança que puede ella sola (siendo parte del todo Español) disputar en forma de Monarquia, con solos sus ingenios» (fol. $2 \mathrm{v}$ ). En efecto, y tras elogiar a san Ignacio y a san Francisco Javier (fols. $7 \mathrm{v}-8 \mathrm{r}$ ), meros pretextos para el interés principal de Ibarra, el poético ${ }^{65}$, el cronista apenas se detiene en rememorar las justas que en honor de ambos santos se celebraron en la ciudad (fols. 8r-15v). La crónica de los siete certámenes, de los que iba a ser juez principal Arguijo si no hubiera muerto antes, iba acompañada, según era habitual, de la publicación de los poemas de los participantes (fols. 16r-83v). Pero Ibarra está más interesado en historiar, avant la lettre, la escuela de los alumnos hispalenses:

Viose Sevilla en sus alumnos, conociolos por el idioma, mirò en ellos ilustrado el resplandor de la elegancia del Marques de Tarifa, la divinidad de Herrera, la

\footnotetext{
${ }^{64}$ Encomio de los ingenios sevillanos. En la fiesta de los Santos Inacio [sic] de Loyola, i Francisco Xavier. A Don Iuan de Villela caballero de Abito de Santiago, del Consejo de su M. i su Presidente en el Real de las Indias. Dedica la Nación de los Caballeros Guipuzcoanos, i Vizcaínos. Por Iuan Antonio de Ibarra, Secretario i Contador del Consulado, i Lonja de Sevilla, Sevilla, Francisco de Lira, 1623. Cito por la edición paleográfica de A. Pérez y Gómez, Encomio de los ingenios sevillanos, Valencia, Tipografía Moderna, 1950.

65 Así, por ejemplo, escribe: «Nacieron los verdaderos Poetas, o para aprovechar, o para deleitar, apartando los oidos, del lenguaje impuro, informando el alma de provechosa enseñança, templandole las passiones de aspereza, de invidia, de ira: Maestros en suma, de la vida» (Encomio..., op. cit., fol. 9v).
} 
erudicion de Pachecos i Medinas, la agudeza i sal de Alcaçares i Salinas, la copia i propiedad de Iaureguis i Guzmanez, el caudal profundo i alteza de espiritu de Francisco de Rioxa i Antonio Ortiz Melgarejo, la grandeza de eroicos pensamientos de D. Iuan de Arguijo i D. Iuan de Espinosa, la comprehension i viveza de Don Alonso de la Serna (fol. 23v).

A la cabeza de tantos ingenios sitúa Ibarra la tríada formada por el marqués de Tarifa, Herrera y Arguijo (fols. 2v-3v), de los que ofrece algunas muestras poéticas. El veinticuatro sería eslabón entre esta tríada y la siguiente promoción: «A este Genio sucedieron» Alonso de la Serna, Juan de Espinosa, Francisco de Rioja y Antonio Ortiz Melgarejo (fols. 3v-5v). Entre estos destaca el cronista a Diego Félix Quijada y Riquelme, en quien Ibarra se detiene especialmente (fols. 5v-7v), hasta terminar llamándolo «La nueva Esperança desta Roma» (fol. 38r). No en vano, nada menos que Lope lo había alabado en la Justa por san Isidro. Cabe indicar que el elogio deparado a Riquelme por Lope, y parafraseado por Ibarra - que se declara amigo de ambos -, en mucho coincide con la carta que Arguijo había escrito a Quijada y que éste había puesto al frente de su colección de ochenta sonetos, las Solíadas: «su dulçura tenia mucho que alabar, nada que reprehender» (fol. 6v) ${ }^{66}$. En 1619, Riquelme acudiría a la Corte con el aval que significaría, a ojos de Lope, lo escrito por Arguijo, y con él se presentaría ante el Fénix, que lo invitaría a las justas madrileñas y luego lo elogiaría en el libro correspondiente (1620), limitándose a parafrasear la carta de su viejo amigo sevillano.

Ibarra sigue añadiendo nuevos autores, como los jesuitas con los que el propio Arguijo habría convivido: Juan de Pineda, Gabriel de Castilla y Diego Martínez (fol. 37v). Y nuevamente elogia al veinticuatro: «El ecelso tanto como amable D. Iuan de Arguijo coluna de los ingenios de su patria, i desprecio del tiempo, que a su pesar le lloran las memorias, i le veneran los que le invidiaron» (fol. 37v), alabanza del carácter y de la generosidad económica (columna) de Arguijo.

Sin duda, el Encomio es obra en la que habría que seguir explorando para hallar nuevas conexiones que nos aportaran -calida iunctura- otras perspectivas sobre la poesía sevillana del manierismo.

\section{Arguijo reenvía su poema a Calatayud (1617)}

Arguijo practicó cuando pudo la generosidad recordada por Ibarra, es decir, entre 1594 y 1606, período en que también adquirió esculturas, encargó

66 Solíadas de D. Diego Félix de Quixada y Riquelme dedicadas en 1619 a Don Francisco de Guzmán Marqués de Ayamonte, ed. M. Pérez de Guzmán y Boza, Sevilla, Oficina de E. Rasco, 1887, pp. xxviixxviii. 
diseños arquitectónicos y gastó en cuadros. Juan de Fonseca y Figueroa retrató al veinticuatro67, y ambos, poeta y pintor (Orfeo y Apeles), fueron elogiados en una silva que convincentemente ha sido atribuida a Francisco de Calatayud:

Dos palmas, dos laureles
para Orfeo y Apeles
prevén, oh tú, que notas admirado
de Arguijo el fiel traslado
y de Fonseca el dibujar valiente,
por famas voladoras
que, desde el rojo Oriente
a donde muere el sol, canten su gloria
y den eterna vida a su memoria. ${ }^{68}$

Este poema ha sido transmitido por un autógrafo que La Barrera atribuyó a Francisco de Rioja ${ }^{69}$. A pesar de las inseguridades de este crítico en lo relativo a la letra de Rioja ${ }^{70}$, y de que él mismo honrada o científicamente reconoció haber cometido la notable «equivocación caligráfica» sobre la «Canción a las ruinas de Itálica» 71 , aceptaron su supuesta pericia sobre la letra de la silva citada López Bueno ${ }^{72}$ y Cobos Rincón ${ }^{73}$. Pero la letra de BNM Ms. 3888, fol. 122r no es de Rioja, porque coincide con los autógrafos de Arguijo que transmiten los manuscritos BNM Ms. 4141, pp. 313-336 y BNM Ms. Res. $262^{114}$.

La correcta descripción física hecha por López Bueno del «papel bastante más pequeño que el resto y con señales de dobleces» que transmite la silva se ajusta - aunque esta autora no lo sospechó - a lo que debió de suceder realmente: la hojita de BNM Ms. 3888 con la silva habría pasado de Arguijo a

\footnotetext{
67 Según Cayetano Alberto de la Barrera: «Francisco Pacheco y don Juan de Fonseca y Figueroa pintaron retratos suyos [de Arguijo] que no parece han llegado a nuestros días» («Apéndice primero...», cit., p. 326).

68 Poesias varias (tejuelo), BNM Ms. 3888 (antiguo M 82), fol. 122r. Debajo de este poema, con letra del siglo XIX (¿de Barrera?), se escribió (y luego se tachó levemente con lápiz): "Autógrafo de Rioja». La convincente atribución del poema a Calatayud es de Mercedes Cobos Rincón, Francisco de Calatayud y Sandoval (vida y obra), Sevilla, Diputación, 1988, pp. 146-148, quien con razón se extraña de que Vranich nunca se refiera a esta silva, quizá por desconocimiento (p. 146, n. 247). ${ }^{69}$ Cfr. Cayetano Alberto de de la Barrera, «Noticias biográficas...», art. cit., p. 87, y sobre todo su edición de Poesías de D. Francisco de Rioja..., Madrid, Rivadeneyra, 1867, pp. 143 y 311 («escrita de mano de RIOJA»); en p. 311 añade que BNM 3888, fol. 122 «Hállase formado [...] por un papel suelto»; «otro papel, foliado con el 123», contiene, «de letra de Calatayud», la silva al retrato de Sarmiento.

70 Cfr. el «probablemente escrito de su mano» (Poesías de D. Francisco de Rioja..., ed. cit., p. 148), que luego atribuye a Pacheco y / o a un amanuense de éste (ibid., pp. 157-158).

71 Ibid., pp. 145-147.

72 Francisco de Rioja, Poesía, ed. Begoña López Bueno, Madrid, Cátedra, 1984, pp. 99-100.

${ }^{73}$ Mercedes Cobos Rincón, Francisco de Calatayud..., op. cit., p. 143.
} 
Calatayud y de éste a Fonseca. Propondré cómo. En el Madrid de 1617, Fonseca estaba presumiblemente preparando una antología - el título con que la noticia circula (Cancionero de poetas andaluces) se le ocurrió en el XVIII a Sedano-, donde al menos iban a figurar textos de Medrano, Alcázar y Calatayud; así lo testimonia una carta fechada en Sevilla, el 13 de junio de 1617, en que este último prometía a Fonseca enviarle copias de los dos primeros y «de los versos menos malos míos, por que no le parezca a Vm. melindre ni excusa»74. Mi hipótesis es que Calatayud se acordaría entonces de la "primitiva» silva con que había obsequiado a Arguijo; así que le pediría un traslado del original, a lo que accedería el veinticuatro. Una vez en su poder la copia hecha por Arguijo de su puño y letra, Calatayud se la reenviaría a Fonseca, quien la conservó entre los materiales que iba a emplear en su fallida colección ${ }^{75}$. Tanto trasiego explica los «dobleces» del papelillo, enviado después de junio de 1617 al menos en dos ocasiones: una por Arguijo a Calatayud, dentro de Sevilla, y otra por éste a Fonseca, desde la ciudad hispalense a Madrid.

\section{Arguijo y su "centuria" de sonetos (1646)}

Recordemos la promesa que Juan de la Cueva hizo a Arguijo en su epístola de h. 1600-1601: «Os prometo, don Juan, hacer docientos / de fábula y de historia». Doscientos sonetos. Ahí es nada. Por su parte, «El prólogo» a las Rimas exentas de Lope (1604) comenzaba así: «Aquí tienes, letor, dos centurias de sonetos...» ${ }^{76}$. Y en 1613 el mismo Fénix - recordémoslo también - aludía en La dama boba a los «Cien sonetos de Liñán», sintagma que debería leerse de nuevo sin cursiva, pues centuria era sobre todo una manera de contar, y no tanto de titular, como hubiese mostrado asimismo la perdida Esfera poética de Rodrigo Fernández de Ribera, obra que gracias a Nicolás Antonio sabemos que estuvo compuesta por

\footnotetext{
74 Ibid., pp. 72-73, por donde cito la carta (BNM Ms. 5781, fol. 162r). Sobre Fonseca, canónigo de la catedral de Sevilla (1610) y habitante en el Madrid de 1606 y de 1613-1617, cfr. Cayetano Alberto de la Barrera, Poesías de D. Francisco de Rioja..., ed. cit., pp. 292-319, 347-348, 350 y 352-354, quien abunda en su colaboración con Calatayud y Rioja (pp. 10, 24 y 93) para el supuesto Cancionero de poetas andaluces (p. 301).

75 BNM Ms. 3888 recoge papeles de Fonseca, entre los que figuraría «parte de lo que iba a ser esta antología - que probablemente no se llegó a concluir -», según Mercedes Cobos Rincón, op. cit., p. 77, a quien pertenece el adjetivo primitiva (p. 147) que acabo de citar. Esta autora apunta en ese lugar que Calatayud compuso esta silva antes que sus otras dos a los retratos de Sarmiento y Rioja, ambos también obra de Fonseca. Yo supongo que éste pintaría a Arguijo antes de su deshaucio en 1606.

${ }^{76}$ Rimas I..., ed. cit., p. 163.
} 
otras tantas centurias de Sonetos, y los nombres dellas: Amorosa, de Venus, dedicada a Lope de Vega Carpio: Fabulosa, de Mercurio, a D. Luis de Gongora; Varia, de Diana, a D. Francisco de Quevedo: Heroica, de Marte, a Doña Christovalina de Alarcon; Jocosa de Jupiter, a D. Juan de Arguijo; Funebre, de Saturno, a D. Juan de Vera y Zuñiga; Sacra, del Sol, a D. Francisco de Rioja.77

Estamos, pues, ante una frecuente $-\mathrm{y}$, por redonda o perfecta, quizá simbólica - forma de agrupación de sonetos. Así que cuando en 1646 alguien indique que Arguijo había empezado su propia centuria, habrá que considerar que se trataba de una colección proyectada de cien sonetos, y no del título de la obra toda: «Centuria que començo a hazer Don Juan de Arguijo 24 de Seuilla »78.

Por lo que sabemos, en efecto, Arguijo comenzó esa colección, pero no la terminó, o no pudo terminarla.

\footnotetext{
77 Nicolás Antonio, Bibliotheca Hispana Nova..., II, Matriti, Viduam et heredes Joachimi de Ibarra, 1788, p. 266a; he citado la traducción de Cayetano Alberto de la Barrera, quien dio por perdidos los setecientos sonetos de la Esfera (Poesías de D. Francisco de Rioja..., ed. cit., pp. 96-97, n. 1; y cfr. pp. 330-332).

78 Sonetos Varios Recogidos [...] Por Don Joseph Maldonado Dauila y Saauedra. Vezino de Seuilla año de 1646, BNM Ms. 20355, fol. 206r.
} 